\title{
Resistance to Anti-Thyroid Drugs in Graves' Disease: Clinical-Biological Characteristics and Alternative Therapy in Tropical Area
}

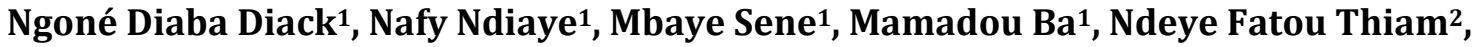 \\ Khadidja Samb1, Pape Momar Guisse'1, Sokhna Awa Balla Sall'1, Aida Diop Diene1, \\ Marylin Zohoun', Yakham Mohamed Leye ${ }^{1}$, Abdoulaye Leye ${ }^{1}$ \\ ${ }^{1}$ Department of Endocrinology, Pikine Teaching Hospital, Cheikh Anta Diop University, Dakar, Senegal \\ ${ }^{2}$ Department of Otorhinolaryngology, Military Hospital of Ouakam, Dakar, Senegal \\ Email: diackngone@gmail.com
}

How to cite this paper: Diack, N.D., Ndiaye, N., Sene, M., Ba, M., Thiam, N.F., Samb, K., Guisse, P.M., Sall, S.A.B., Diene, A.D., Zohoun, M., Leye, Y.M. and Leye, A. (2020) Resistance to Anti-Thyroid Drugs in Graves' Disease: Clinical-Biological Characteristics and Alternative Therapy in Tropical Area. Open Journal of Endocrine and Metabolic Diseases, 10, 147-153. https://doi.org/10.4236/ojemd.2020.1011014

Received: November 3, 2020

Accepted: November 26, 2020

Published: November 29, 2020

Copyright $\odot 2020$ by author(s) and Scientific Research Publishing Inc. This work is licensed under the Creative Commons Attribution International License (CC BY 4.0).

http://creativecommons.org/licenses/by/4.0/ (c) (i) Open Access

\begin{abstract}
Background: Resistance to anti-thyroid drugs (ATDs) is a rare entity recently described. We report two African observations in the treatment of Graves' disease. Case 1: A 19-year-old Senegalese woman presented on admission with thyrotoxicosis syndrome associated with diffuse goitre and Grave's orbitopathy. TSH levels were low $(0.005 \mathrm{mIU} / \mathrm{ml} ; \mathrm{N}=0.27-4.20)$ and $\mathrm{fT} 4$ elevated $(60 \mathrm{pmol} / \mathrm{L} ; \mathrm{N}=12-22$ ]. Combination therapy with propranolol (40 $\mathrm{mg} /$ day) and carbimazole (starting dose of $45 \mathrm{mg}$ /day and increased to 60 $\mathrm{mg} /$ day) was initiated. In view of the persistence of symptoms despite good therapeutic compliance, carbimazole was replaced by methimazole with an initial starting dose of $40 \mathrm{mg}$ /day, followed by $60 \mathrm{mg} /$ day. Despite the change in therapy, clinical symptoms of thyrotoxicosis persisted, and fT4 levels remained elevated. The patient was diagnosed with resistance to ATDs in Graves' disease. Total thyroidectomy following 10 days of preoperative preparation with $1 \%$ Lugol's solution was performed successfully. Case 2: A 22-year-old woman was referred for continued management of Graves' disease with elevated thyroid-stimulating hormone receptor antibody (TRAb) levels (34 UI/mL; $\mathrm{N}<1.75)$. Treatment included propranolol $(80 \mathrm{mg} /$ day) and carbimazole at an unusual dose of $80 \mathrm{mg} /$ day. Combined therapy was clinically and biologically ineffective, with an fT4 level of $100 \mathrm{pmol} / \mathrm{L}$ [N: 12 - 22]. Upon admission, methimazole $(40 \mathrm{mg} /$ day) followed by propylthiouracil $(800 \mathrm{mg} /$ day) replaced carbimazole. Despite good patient compliance, the patient's symptoms remained unaltered and fT4 levels elevated. A total robot thyroidectomy using the right axillary approach was performed successfully after 10 days of preoperative preparation, including prednisone $(40 \mathrm{mg} /$ day) combined with
\end{abstract}


1\% Lugol's solution. Conclusion: Resistance to ATDs complicates the management of Graves' disease. Total thyroidectomy following preoperative preparation with Lugol's solution and/or corticosteroids was shown to be successful.

\section{Keywords}

Resistance, Antithyroid Drugs, Graves' Disease, Lugol's Solution, Africa, Senegal

\section{Introduction}

Graves' disease is an autoimmune disorder marked by the presence of thyroidstimulating hormone receptor antibody (TRAb) [1]. It is the most common cause of hyperthyroidism [1]. The prevalence of Graves' disease in Senegal is estimated to be approximately $4 \%$ [2].

The initial management of Graves' disease is based on the administration of an adequate dose of anti-thyroid drugs (ATDs). These molecules have been shown to be effective in restoring euthyroidism [3]. However, exceptional cases of resistance to ATS have been described during the management of Graves' disease [4] [5] [6]. Such cases are characterized by the persistence of thyrotoxicosis and hyperthyroidism in patients on an optimal dose of ATDs for at least 6 months with good patient compliance and at least one substitution of the ATD type. Resistance complicates the management of Graves' disease, especially in Africa, where access to other therapies is often difficult.

The present study describes two cases of resistance to ATDs during the management of Graves' disease at the Endocrinology department of Pikine Teaching Hospital. Clinical-biological characteristics and the alternative therapy used are presented.

\section{Case 1}

The first case was a 19-year-old Senegalese woman in preparatory class. She had progressive weight loss with a suppressed appetite, insomnia, and palpitations for 3 months. There was no medico-surgical pathology in the patients' personal history.

On admission, the patient's blood pressure was $140 / 80 \mathrm{mmHg}$, heart rate 122 beats/minute, and body temperature $36.2^{\circ} \mathrm{C}$. Clinical examination revealed a WHO grade 2 goitre [7] associated with thrill and acquired bilateral orbitopathy.

TSH levels were low at $0.005 \mathrm{mIU} / \mathrm{ml}[\mathrm{N}=0.27-4.20]$ and high fT4 levels at $60 \mathrm{pmol} / \mathrm{L}$ [12 - 22]. Initial pharmacological treatment using a combination of propranolol (40 mg/day) and Carbimazole $45 \mathrm{mg} /$ day was initiated. The dosage of Carbimazole was increased to $60 \mathrm{mg} /$ day after 3 months due to the lack of clinical and biological improvement of thyrotoxicosis. Treatment was monitored 
and did not reveal any abnormalities. Complete blood count (CBC), transaminases, and renal function were normal.

In view of the persistence of symptoms despite good therapeutic compliance, carbimazole was replaced by methimazole at an initial dose of $40 \mathrm{mg} /$ day, followed by $60 \mathrm{mg} /$ day. Despite the change in drug therapy, clinical symptoms of thyrotoxicosis persisted (palpitations, weight loss), and fT4 values remained elevated (Figure 1).

The diagnosis of resistance to ATDs in Graves' disease was retained. Surgical treatment of total thyroidectomy was undertaken. ATD therapy was stopped, and Lugol's solution $1 \%$ was prescribed for 10 days. No intraoperative and postoperative complications were reported. Currently, the patient is on hormone replacement therapy (L-Thyroxine $150 \mathrm{ug} /$ day).

\section{Case 2}

A 22-year-old woman was referred for continued management of Graves' disease that had progressed for 2 years. She presented peripheral hyperthyroidism associated with acquired orbitopathy and elevated TRAb (34 UI/mL; $\mathrm{N}<1.75)$. On admission, the patient's treatment included propranolol $80 \mathrm{mg} /$ day and Carbimazole $80 \mathrm{mg} /$ day. Treatment was ineffective, and thyrotoxicosis symptoms persisted.

At admission, the patient's had a blood pressure of $150 / 90 \mathrm{mmHg}$, a heart rate of 112 beats/minute, a temperature of $37.2^{\circ} \mathrm{C}$, and a BMI of $19.4 \mathrm{~kg} / \mathrm{m}^{2}$. Clinical examination revealed diffuse WHO grade 3 goitre [7], bilateral orbitopathy, and muscle weakness.

Laboratory analysis revealed decreased TSH levels of $0.002 \mathrm{mIU} / \mathrm{mL}[\mathrm{N}=0.27$ - 4.20] as well as an increase of fT4 levels ( $100 \mathrm{pmol} / \mathrm{L} ; 12$ - 22]. Thyroid ultrasound showed heterogeneous goitre with increased circulatory speeds on Doppler (Figure 2).

Methimazole was introduced as a replacement for Carbimazole at a dose of 40 mg per day. Beta-blocker therapy was maintained. The patient experienced a discreet clinical improvement, with a slight decrease in fT4 levels (Figure 3) despite good patient compliance. However, TSH levels remained low (Figure 4). Following Methimazole therapy cessation, Propylthiouracil (PTU) was started with a dose of up to $800 \mathrm{mg} /$ day. Symptoms remained constant, and fT4 levels elevated (Figure 3).

The patient's therapeutic failure motivated the reintroduction of Carbimazole at a dose of $60 \mathrm{mg} /$ day. Two months after initiating Carbimazole therapy, fT4 levels remained above $50 \mathrm{pmol} / \mathrm{L}$.

The next therapeutic step was a total robot thyroidectomy using a right axillary approach, which was performed successfully. Preoperative preparation included the initiation of oral corticosteroid therapy (prednisone) at a dose of 40 $\mathrm{mg} /$ day combined with $1 \%$ Lugol's solution at a rate of 45 drops divided into three doses over 10 days. 


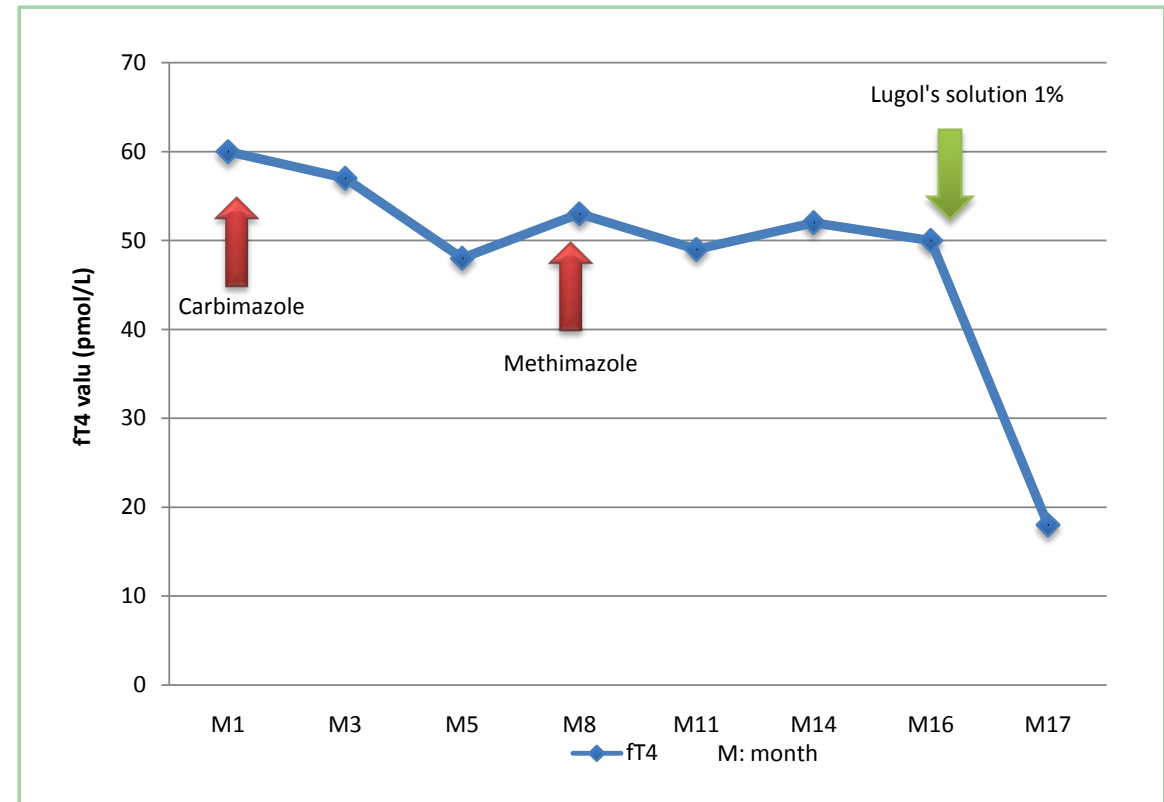

Figure 1. Progression of fT4 levels during the follow-up of case 1.
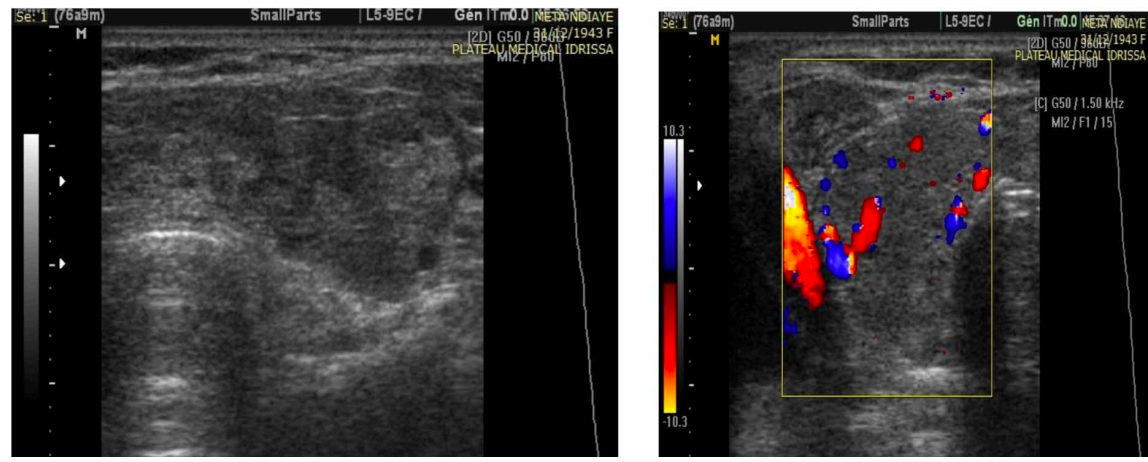

Figure 2. Heterogeneous goitre with increased circulatory speeds on Doppler in thyroid ultrasound of case 2 .

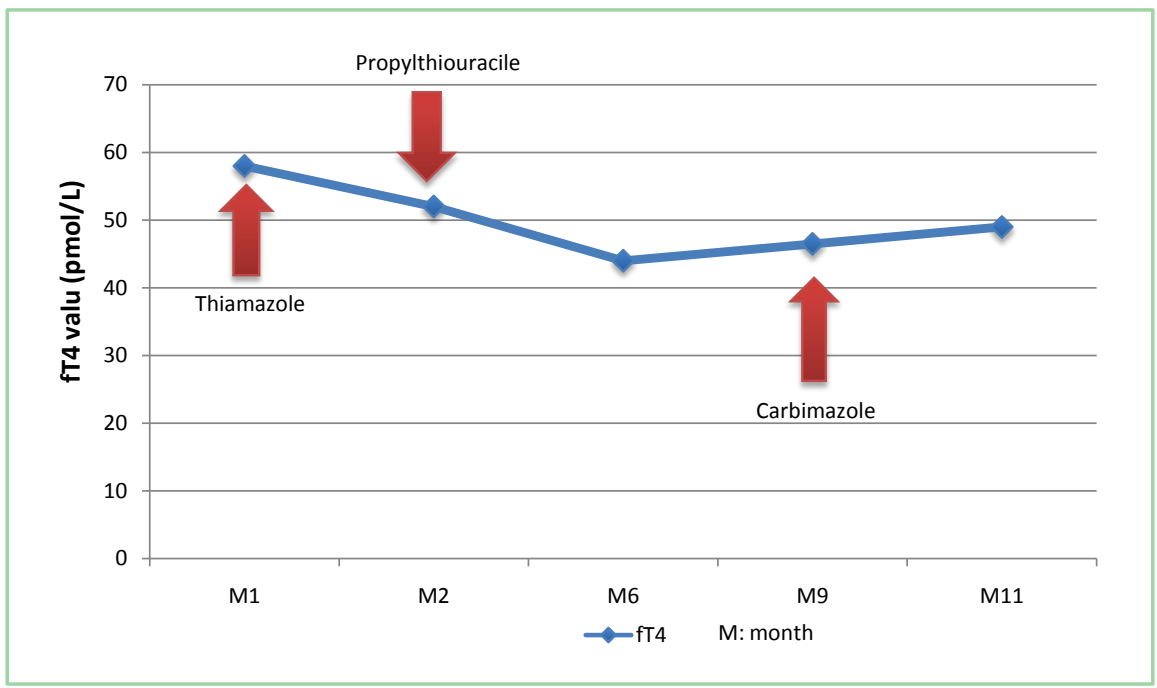

Figure 3. Progression of fT4 levels during the follow-up of case 2. 


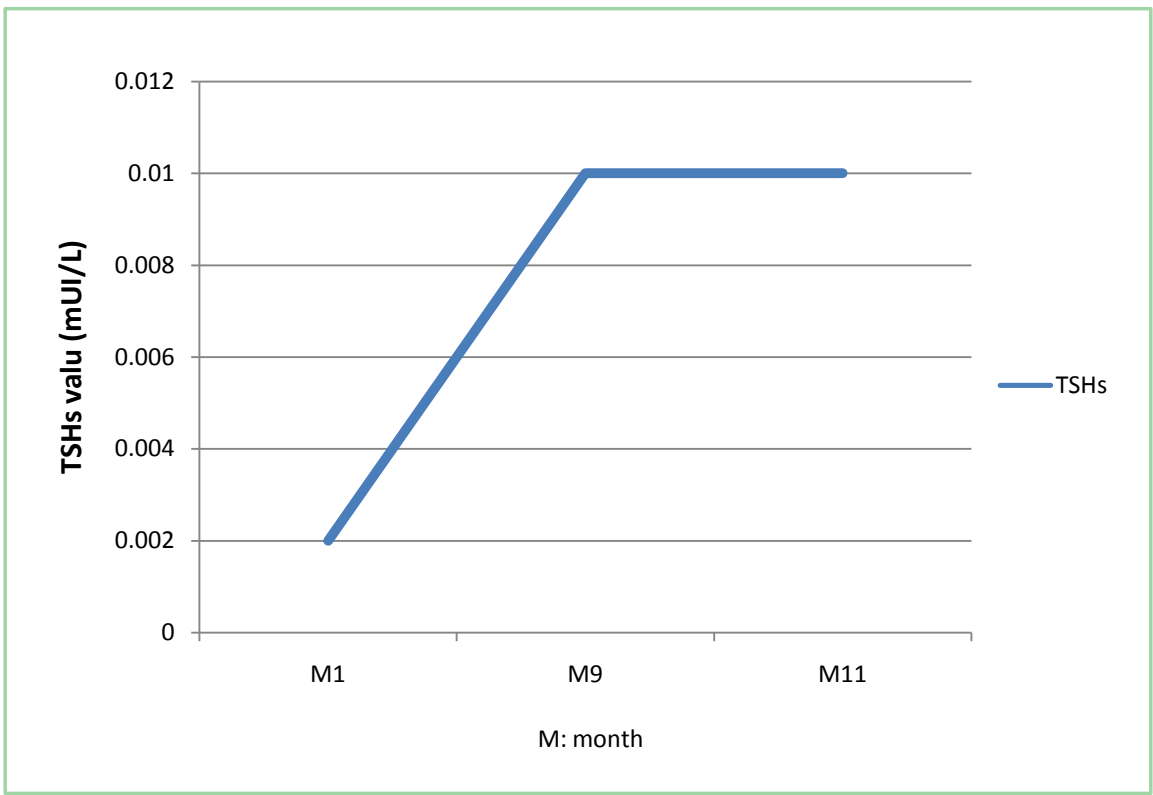

Figure 4. Progression of TSHs levels during the follow-up of case 2.

\section{Comments}

ATDs have been used for the treatment of Graves' disease for several decades [3]. They are effective in achieving rapid euthyroidism, as well as a low risk of progressing to permanent hypothyroidism compared to other therapies. Therefore, ATDs are the first choice of treatment in Graves' disease [1] [3].

However, exceptional cases of resistance to ATDs have been described during the management of Graves' disease and are mainly resistant to methimazole [4] [5] [6].

In this study, we reported two new observations of resistance to ATDs. The patients were two young women that presented with Graves' disease and orbitopathy. The clinical-biological monitoring enabled the diagnosis of resistance to several ATDs, despite good patient compliance.

Indeed, clinical symptoms persisted, and fT4 levels were higher in the two patients after at least 6 months of treatment with carbimazole. Despite the substitution of carbimazole with methimazole or PTU, fT4 values remained elevated. Drug intake that interfered with fT4 values, such as amiodarone, were noted taken by the two patients.

TSH was blocked throughout the follow-up period. However, this observation has been described during the follow-up of Graves' disease, apart from resistance to ATDs [1].

The mechanisms behind resistance to ATS are poorly understood [8] [9]. The MDR-1 multidrug resistance gene, which is responsible for resistance to a wide variety of drugs in human cells, is potentially involved [10]. It is the result of a loss-of-function mutation in the P-pg glycoprotein gene involved in the transport of immunosuppressive drugs and chemotherapeutic agents [11]. In Graves' disease, elevated MDR-1 gene expression levels are associated with disease activ- 
ity and treatment resistance [10]. However, testing for an MDR-1 mutation is not currently recommended and was not performed in the patients in this study.

In addition, daily events are of major importance in the onset of Graves' disease, its flare-ups, and potentially the drug treatment failure [1]. The two patients in the present study were final class students with a pending major examination.

Recent studies demonstrated that low baseline thyroglobulin autoantibodies are associated with refractoriness of Graves' disease to ATD treatment [8] [9]. Therefore, they could serve as biomarkers to predict the failure of ATD treatment in such patients.

Alternative treatment for ATDs resistance is not codified. Generally, surgery following preoperative preparation is recommended. The risk of an acute thyrotoxic crisis, however, remains.

Total thyroidectomy following preoperative treatment using Lugol's solution, beta-blockers, and, in one case, corticosteroids, was the chosen therapy. In our experience, this regimen facilitated clinical-biological regression of hyperthyroidism without any specific per- or post-operative complications.

Other alternatives have been proposed in such cases, such as cholestyramine and plasma exchange for the rapid development of euthyroidism before surgery [6] [12] [13]. Furthermore, a herbal decoction of Anemarrhena Bounge is potentially effective in patients with resistance to ATDs and is a therapeutic avenue warranting future exploration [5].

\section{Conclusion}

Resistance to ATDs is a recently described rare entity. The main hypothesis proposed that explains this drug resistance is of genetic origin. In Graves' disease, the most common cause of hyperthyroidism, the occurrence of resistance to ATDs, complicates treatment, especially in Africa, where access to other therapies is difficult. Rapidly performed thyroid surgery supervised by sound preoperative preparation with Lugol's solution and/or corticosteroids has been successfully in the present study.

\section{Conflicts of Interest}

The authors declare no conflicts of interest regarding the publication of this paper.

\section{References}

[1] Subekti, I. and Pramono, L.A. (2018) Current Diagnosis and Management of Graves' Disease. Acta Medica Indonesiana, 50, 177-182.

[2] Diagne, N., Faye, A., Ndao, A.C., Djiba, B., Kane, B.S., Ndongo, S., et al. (2016) Epidemiological, Clinical, Therapeutic and Evolutive Aspects of Basedow-Graves Disease in the Department of Internal Medicine at CHU Aristide Le Dantec, Dakar (Senegal). The Pan African Medical Journal, 25, 6. https://doi.org/10.11604/pamj.2016.25.6.7868 
[3] Okosieme, O.E. and Lazarus, J.H. (2016) Current Trends in Antithyroid Drug Treatment of Graves' Disease. Expert Opinion on Pharmacotherapy, 17, 2005-2017. https://doi.org/10.1080/14656566.2016.1232388

[4] Li, H., Okuda, J., Akamizu, T. and Mori, T. (1995) Hyperthyroid Patient with Graves' Disease Who Was Strongly Resistant to Methimazole: Investigation on Possible Mechanisms of the Resistance. Endocrine Journal, 42, 697-704. https://doi.org/10.1507/endocrj.42.697

[5] Kim, J. and Kim, T.H. (2018) A Methimazole Resistant Patient with Graves' Disease (GD): A Case Report of Mid-Term Management with Herbal Decoctions Mainly Composed of Anemarrhena bunge. Complementary Therapies in Medicine, 39, 109-113. https://doi.org/10.1016/j.ctim.2018.05.015

[6] Chae, H.B., Kim, E.S., Lee, Y.I. and Min, B.R. (2016) A Case of Methimazole-Resistant Severe Graves' Disease: Dramatic Response to Cholestyramine. International Journal of Thyroidology, 9, 190-194. https://doi.org/10.11106/ijt.2016.9.2.190

[7] Perez, C., Srimshaw, N.S. and Munoz, J.A. (1958) Technique of Endemic Goitre Surveys. In : Endemic Goitre. WHO Monogr Ser 44, WHO, Geneva, 369-383.

[8] Katahira, M. and Ogata, H. (2016) Thyroglobulin Autoantibodies Are Associated with Refractoriness to Antithyroid Drug Treatment for Graves' Disease. Internal Medicine, 55, 1519-1524. https://doi.org/10.2169/internalmedicine.55.6095

[9] Mizuguchi, Y., Morimoto, S., Kimura, S., Takano, N., Yamashita, K., Seki, Y., et al. (2018) Prediction of Response to Medical Therapy by Serum Soluble (pro)Renin Receptor Levels in Graves' Disease. PLoS ONE, 13, e0195464.

https://doi.org/10.1371/journal.pone.0195464

[10] Kim, R.B., Leake, B.F., Choo, E.F., Dresser, G.K., Kubba, S.V., Schwarz, U.I., et al. (2001) Identification of Functionally Variant MDR1 Alleles among European Americans and African Americans. Clinical Pharmacology \& Therapeutics, 70, 189-199. https://doi.org/10.1067/mcp.2001.117412

[11] Muralidharan, N., Antony, P.T., Jain, V.K., Mariaselvam, C.M. and Negi, V.S. (2015) Multidrug Resistance 1 (MDR1) 3435C> T Gene Polymorphism Influences the Clinical Phenotype and Methotrexate-Induced Adverse Events in South Indian Tamil Rheumatoid Arthritis. European Journal of Clinical Pharmacology, 71, 959965. https://doi.org/10.1007/s00228-015-1885-0

[12] Sebastián-Ochoa, A., Quesada-Charneco, M., Fernández-García, D., Reyes-García, R., Rozas-Moreno, P. and Escobar-Jiménez, F. (2008) Dramatic Response to Cholestyramine in a Patient with Graves' Disease Resistant to Conventional Therapy. Thyroid, 18, 1115-1117. https://doi.org/10.1089/thy.2008.0094

[13] Tieken, K., Paramasivan, A.M., Goldner, W., Yuil-Valdes and Fingeret, A.L. (2020) Therapeutic Plasma Exchange as a Bridge to Total Thyroidectomy in Patients with Severe Thyrotoxicosis. AACE Clinical Case Reports, 6, e14-e18.

https://doi.org/10.4158/ACCR-2019-0132 